\title{
Help! I'm New to Licensing and Don't Know Where to Start
}

\author{
BREEZY SILVER \\ Michigan State University, East Lansing, MI \\ silverbr@msu.edu
}

TIPS

\begin{abstract}
Column Introduction For those of us that deal with database or data set licenses, it can be quite a daunting task (especially within the business resources realm). The complexities involved with access, download restrictions, and other terms of use embedded in the license can lead to frustration and confusion. In this article, Breezy Silver discusses some of the tips and tricks that can be used to help manage this complex document. Breezy also offers some words of encouragement that can be used during the negotiation process as well. - Ryan Splenda and Eve Wider, Column Editors
\end{abstract}

When one first sees a license, it can be an intimidating, long document of jargon for anyone without a law degree. Most licenses tend to be extensive, while an occasional one can be brief. Business resources and database licenses can add their own challenge, since many come from companies in the corporate arena, and they do not translate well to academia and our needs. Some companies are so new to academia that they do not know that academia uses resources differently than the corporate world. That means the licenses may need some extra work to make them fit our needs. Here are some basic recommendations to keep in mind when wading through that document coming from someone with no law degree who has already done a fair amount of wading to learn licensing.

\section{Getting Started}

Before getting started, you need to identify your deal-breakers that cannot be in the license or on the flip side must be included in the license. For example, you may require that an indemnity clause is not in the license or add a clause that walk-in users must be permitted users. You will also want to think of the content that would be nice to have but would not kill the deal if you did not get it. For instance, do you need the ability to allow interlibrary loan for journals or e-books and if they don't is it a deal-breaker or is it one of the nice-to-have options? These requirements could change depending on the type of content (i.e. articles, books, reports, or data) and the users you expect to use it. Interlibrary loan may be a dealbreaker for books and journals, but not for databases or data for some institutions. However, you may be willing to make exceptions. For example, if you require the jurisdiction and currency to be within the United States, but you have a relatively inexpensive journal that is international, you might be willing to forgo those requirements. These requirements will also vary from institution to institution and even departments within the institution. So before you get started, you need a clear understanding of what you are buying and who will use the content. You may need to talk to administration to figure out those dealbreakers and desired content. Before you begin you also want to make sure you are aware of any institutional rules that you must follow. This could include the requirement to include accessibility language. You also need to make sure you know who has signatory rights at your institution. The person reviewing the license may not be the same person able to sign it so make sure you're following your institution's process for license review. 
When reviewing the document, take it one sentence at a time, using a ruler if needed, to keep track of placement. There could be paragraphs with long run-on phrases or even repeating sentences, and let's be honest, it can be boring, causing you to drift off. So obviously reviewing a license in your post-lunch haze is not a great idea. It definitely helps to take a sentence or clause a little at a time so you do not get overwhelmed while trying to figure out what they are really trying to say. When you are ready to dig into the license, here are some considerations to keep in mind as you are reading it. These may also help you to clarify your deal-breakers and desired content.

\section{Who are the Permitted Users?}

Who are you buying this for, and does that match what is permitted in the license? Is access for a single faculty member, a department, or an entire campus? As a university library, you may typically purchase for all university faculty, staff, and students, or if affiliated with a college or school, only for those in your subject/discipline area. If it is data, do they limit direct access to specific people (i.e., librarians) who are then the gatekeepers of the data to your users? Do you also purchase for the public who walk into the library? If so, walk-in users need to be permitted. Some institutions may also negotiate for alumni or technology (tech) transfer office access. Typical access is granted to current affiliates of the institution for academic purposes only. Since alumni are no longer current affiliates and tech transfer offices do commercial work rather than academic, this is typically something extra you would have to negotiate and there could be a higher cost associated with it.

\section{What are the Access Methods?}

Is it available via IP address or user logins? IP access may be preferred so you do not have to manage individual logins which may happen with this type of access. If you have walk-in users, then having logins may require assistance from staff to log in if they are permitted to log in at all. Is off-campus access permitted? Does it work with a proxy server? Is access limited to a building? Keep in mind that IP access does not equal off-campus access. The database can operate with IP addresses but can still be limited to a particular computer or building. Alternatively, it may not even work with your proxy server. Since some databases price differently based on the number of perceived users, you may have no choice but to limit access due to budgets. The important thing is to make sure that what you are expecting for the database access matches what it says in the license.

There have also been recent cases where vendors have been moving away from IP access to single sign-on. Single sign-on requires the use of logins rather than IP addresses for access. This method of access may cause concerns over user privacy, technological feasibility, and can be a time-intensive process to set up. Also, it puts up a roadblock for any walk-in users because they do not have institutional credentials. Keep in mind that the vendor may change access suddenly, making it difficult or impossible for you to use. Your license is your best protection, and you should consider using clear and strong language on the access methods expected to be available and your ability to get out of the agreement if access is significantly changed. You do not want any wiggle room for the vendor to deny that they are breaking the license. This becomes incredibly important when considering a multi-year agreement when future issues may not yet be known. Unfortunately, there are also some unscrupulous vendors, so you want to use your license to your benefit to protect yourself. If single sign-on is an acceptable possibility for access, you may want to think about privacy issues and making sure things are handled well in the 
Ticker: The Academic Business Librarianship Review, 4:1 (2019)

http://dx.doi.org/10.3998/ticker.16481003.0004.104

(c) 2019 Breezy Silver

license. For example, does it mention anything about FERPA (Family Educational Rights and Privacy Act of 1974), which protects student records?

Some other thoughts to keep in mind regarding access include the question of whether there are additional costs for satellite or multiple campuses. Is it perpetual access or a rental? If perpetual, what is included? For example, if it is for journals, make sure there is a complete title list. What happens after your subscription is canceled or a title is removed? If a significant portion of content is dropped, what happens? See if alternative content is added or whether you have the ability to cancel your subscription and receive a prorated portion of your fees back. How are you guaranteed access if you have perpetual access? Do they send a hard drive or provide some other online access?

\section{What is the Term Length and Payment Information?}

What is the term length or how long does the agreement last? Typically, this is a year. What does it say about renewals? Does it automatically renew for another term? What does it say about the cost of the product? Is it in your country's currency? It is generally best to have it in your currency so fluctuations in exchange rates do not affect it as much. Does it include a built-in percentage for renewal cost increases? Most do not specify a rate of increase, but it is possible. Do they require a certain payment method that works for you? If you use purchase orders and checks, a credit card requirement will not work. How long do they give you to pay the bill? Remember, payment requests at academic institutions can take time to make it through the accounting system, so 7-10 days may not be long enough. Thirty days is a more standard number. Is there a late fee if it is paid late? Some licenses even request all related reimbursement costs related to a late payment including attorney costs. Are these late fees acceptable or would turning off access alone suffice? Leaving your institution open to unexpected costs with unknown late fees may not be acceptable. How do you cancel your subscription? Do you have to give notice within a certain time frame using a particular method? For example, would an email work? If you fail to cancel in time, does it automatically renew even if the current term is not up yet?

\section{What are the Permitted Uses?}

Are there restrictions on printing, viewing, downloading, or saving? For example, are users only able to download a limited amount of content at a time? Vendors can be protective of their content, which is understandable, but sometimes they can be a little too restrictive for the use you need. In this case, you may want to explain that you understand their concerns, but also state your needs and why you need to loosen the restrictions for people already approved to use the content. Providing examples of better terms used by competitors may help. Is there a restriction on interlibrary loan or uses permitted under copyright? Are you signing away your rights with copyright? It is always nice to see in a license that it allows use under copyright laws. Most licenses also typically allow for academic use only with commercial use prohibited. So you want to make sure your use matches the license, and as previously mentioned, you could negotiate for tech transfer office type of access if more commercial use will occur.

\section{Are there Additional Uses?}

Are you allowed to use the content in course packs? Is data or text mining permitted? Some vendors will charge extra for use in course packs or for data mining capabilities, but if it is allowed and permitted in the license, that is worth knowing. If it is important to you, you can try to get it added. Whether they are 
Ticker: The Academic Business Librarianship Review, 4:1 (2019)

http://dx.doi.org/10.3998/ticker.16481003.0004.104

(c) 2019 Breezy Silver

permitted or not, you may want to make sure that information is shared with other interested parties in your institution.

\section{Is there an Indemnification Clause?}

If there is an indemnification clause, you may be financially responsible for damages if any of your users misuse the content. They may make you responsible for your users' behavior which can be very difficult if not impossible for a library to control. It also exposes your institution to unknown costs. You may want to consider this a deal-breaker. If the vendor will not remove it, you could see about adding an extra clause that says you are not liable as long as you did not intentionally or through gross negligence allow a breach.

\section{Extra Requirements}

If it is a subscription or rental deal, do they require all users to delete any content they have downloaded after cancellation? Do they ask that you verify in writing that users have done so? Do they require that users delete any content they have downloaded after they graduate or leave your institution? For example, if you purchased a dataset, do they want all users to delete any data that they downloaded when they are no longer affiliated? Do they require that you keep track of all of the users who use the content? Keep in mind that we cannot control users' behaviors and you probably do not have any way to confirm that all of your many users have deleted the content they used. You may not have the resources to track users and even if you do, would you want to share that information with a vendor? Do you have to make sure all users are aware of any terms of use? If so, how do you do this? Do you provide a vendorspecific click-through for each resource that requires this or provide a link to it? Alternatively, you could consider creating a more generic database usage policy page click-through to put in front of databases. Would the vendor accept that? If not, would it be better if they had a click-through agreement on their site rather than the library? Do you have to notify the vendor any time someone publishes anything using their content? Do they require a specific citation? The publishing and citation requirements could be more of those requirements that are difficult to achieve since we cannot force users to do anything. Do the vendors require that they are allowed to visit you and review your records anytime? Would your administration allow a third party to come in and review your system and records? Do they require a nondisclosure agreement? Vendors typically want this included so you are unable to share the price you paid for the database or any other information about their database. However, what do you do if there is a government warrant or if you are a public institution subject to FOIA (Freedom of Information Act)? There should be exceptions that allow for these things at the minimum. Do they want to use your institution's logo in their advertising? Some institutions may limit third party access to their brand so this may be something you cannot accept. Does the license mention an additional set of terms of use found elsewhere? This is a concern because the vendor can change these terms at any time, and they are not negotiated. If there are additional terms, at least make sure you read them and perhaps include them in your negotiation, thus preventing any changes to the additional terms without another review. You may also find other unexpected requirements, as it is difficult to account for everything that may show up in a license. The important thing to remember is to make sure to read the license fully so you understand what it says and can then decide what to do. 


\section{Jurisdiction}

What if there is a conflict? How is it handled according to the license? What court jurisdiction is used? If you are a public institution, does your state government require the local state to be the jurisdiction? Is it international? Remember you need representation in an international court so you may want the governing jurisdiction to be in your home country. Do they use arbitration instead?

\section{Accessibility}

Are the products ADA compliant? If not, do they address identified violations at no cost, and, if so, how quickly? Do they provide a Voluntary Product Accessibility Template (VPAT)? The Big Ten Alliance has some standardized language for licenses you may want to try to incorporate. You can find it here: https://www.btaa.org/library/accessibility/library-e-resource-accessibility---standardized-license-language.

\section{Final Words of Encouragement}

Each library will have their own deal-breakers, preferences, required additional clauses, and other items for which flexibility may be required. This could also change among type of content like data versus journals, the cost of the product, and who is accessing it. So even within your own library you may have to be willing to be flexible on what matters most to you in a license agreement. Your aim is to provide a resource while working to protect the library and its users, understanding that the vendor is trying to protect their content, too.

Suggest alternative language that better suits you or ask that content be removed or added. If you can't get the vendor to remove disagreeable content, try to add language to give you wiggle room - like "best efforts," "reasonable efforts," "technically feasible," etc. For example, "Licensee must notify users of license terms of use" can be changed to "Licensee must make reasonable effort to notify users of license terms of use." It seems basic but also make sure all of the information is correct including licensee names, any contact information, pricing information and all dates including term period and effective date.

How much are you willing to give in to the vendors' demands? If you have identified what is absolutely required, be prepared to walk away from the deal if they are not met. Unfortunately, this does happen, but most of the time you can come to an agreeable compromise.

Do not be afraid to negotiate and do not automatically accept any terms or prices. You will be amazed what you can get just by asking. Vendors are not our enemies. They are trying to sell a product, and as an employee of an institution, you must be a good steward of resources that benefit your users. You can work together to find some mutually beneficial ground.

\section{Additional Resources}

This is not an exclusive list of the concepts, requirements, or issues you may encounter as this article is only meant to get you started. There are resources available for additional information:

- $\quad$ LIBLICENSE (http://liblicense.crl.edu/)

Includes model licenses, license vocabulary, and other resources. They also have a listserv to make it easier to communicate with others. 
Ticker: The Academic Business Librarianship Review, 4:1 (2019)

http://dx.doi.org/10.3998/ticker.16481003.0004.104

(c) 2019 Breezy Silver

- Electronic Resources in Libraries Email List (http://www.eril-I.org/)

This listserv is for broad electronic resources discussion that also includes licensing.

- Harris, L. E. (2018). Licensing digital content: a practical guide for librarians. Chicago: ALA Editions.

- Lipinksi, T. A. (2013). The librarian's legal companion for licensing information resources and services. Chicago: Neal-Schuman. 